\title{
SPATIAL FOUNDATIONS \\ FOR ADDRESSING THE STATISTICAL NEEDS OF \\ THE RECONSTRUCTION AND DEVELOPMENT PROGRAMME
}

\author{
JA KAHIMBAARA \\ Statistics Adviser \\ Directorate of Statistics \\ Department of Economic Affairs \\ North West Province \\ South Africa
}

\section{INTRODUCTION}

The objective of the seminar is to identify the challenges of the RDP and to find ways that statisticians and operations researchers can contribute towards meeting these challenges.

The challenges of the RDP are many and varied, and cannot be addressed in a single presentation. For this reason I would rather concentrate on a single challenge which I regard as an extremely fundamental one - laying the spatial foundations for addressing the statistical needs of the Reconstruction and Development Programme (RDP).

For the substance of this paper I have liberally drawn upon the work of the Directorate of Statistics in the Department of Economic Affairs in the North West Province and 1 would also like to acknowledge the contributions of Professor H S Geyer of the Institute of Urban and Regional Planning of Potchefstroom University for Christian Higher Education (PUCHE). Professor Geyer's contributions are treated as a contribution from PUCHE. 


\section{CONCEPTUAL FRAMEWORK}

Before I present the spatial foundations for addressing the statistical needs of the RDP, I would like to outline the conceptual framework within which our work was conducted.

\section{Cornerstones of Apartheid}

We hold as unequivocally true that the challenges of the RDP are essentially the challenges of transforming South African society from an apartheid society to a democratic one. And in order to effect such a transformation, we need to remove the cornerstones or the key variables of the policy of apartheid. The three key, or macro, variabies are: legislation, public institutions and spatial segregation. I wish to argue that of these three macro-variables only two, legislation and public institutions, have been given sufficient attention in the transformation process, and that the third macro-variable, spatial segregation, has been rather neglected.

The role of legislation in the formulation and enforcement of the policy of apartheid is so well known that it needs no further elaboration here. However, we need to note that legislation was the most important of the three apartheid macro-variables as demonstrated by its role in initiating the transformation process. Understandably a lot of effort has been expended in removing apartheid legislation, undertaken by the national and provincial legislatures as well as by local authorities. Constitutional development is currently the most prominent aspect of this change. The point here is that legislative apartheid is being eradicated.

The transformation of public institutions as a macro-variable of the policy of apartheid and its legacy is also receiving a lot of attention although the transformation in this respect is not as smooth as in the legislative case. It is hoped, however, that this key variable is also being satisfactorily transformed. 
Unfortunately, however, the efforts spent at removing spatial segregation have not been as great as in the case of the other two macro-variables, as spatial reorganisation of the country has been confined largely to the national level, ending with the re-organisation of provincial boundaries. Apart from the North West Province, little has taken place elsewhere in terms of removing spatial apartheid by way of re-integrating the geographic space of the provinces.

\section{Spatial Organisation of Apartheid}

The spatial or geographical expression of the policy of apartheid has been the creation of homeland (self-governing states and nation states) and townships, both of which have acted as labour reservoirs and consumer communities with very little internal development. The space was so arranged that people from these enclaves had to cross boundaries to export their labour and to spend their incomes on consumer goods. The fact that there is no apartheid left on the books is hardly a guarantee that the spatial configuration of the policy of apartheid will not entrench its legacy. The dynamics of spatial apartheid will continue unabated, with administrative centres, which have no justification for being such, maintaining their privileges, with areas which had the growth advantages of Regional Services Councils fortifying those advantages, and so on, so that the various sections of the space are likely to maintain their relative levels of benefits, burdens or impoverishment in the new dispensation. We believe that this state of affairs is not part of the transformation process; hence the need and urgency to restructure the geographic space of the provinces. Spatial re-organisation is urgent in view of the impending Local Government Election this November. The concern here is that once space is demarcated into political units below the magisterial district level for local government, and representatives are elected, these units are likely to assume permanence such that their boundaries are fossilised. If these units are demarcated on an untransformed provincial space, changing them later will be almost an impossibility. 
As early as 1993, the Directorate of Statistics in the Department of Economic Affairs in the North West Province saw the need to be pro-active in the face of the pending transformation of South African society. The objective was to put in place a statistical information management system that would meet the needs of the public service as well as the private sector and the public at large where this was possible. As a result, plans for a Statistical Information Management System (SIMS) were developed and implemented.

The rationale for the SIMS was twofold. Firstly, the SIMS was seen as an integral part of the transformation process as it was partly meant to re-integrate the geographic space of the North West Province after the re-incorporation of the Bophuthatswana homeland. Secondly, the SIMS was conceived as an innovation to create a statistics system in the Province whereby statistical information would be holistically managed and accessed. Of concern was a lack of standardisation for the production of statistical information due to the fact that statistics were often produced by various agencies which were not aware of one another's activities. Work was consequently often duplicated and the methodology was also very often variable both procedurally and spatially. It was thus deemed necessary that the managers in the new government be given an opportunity to be provided with information for input into their planning and decision-making in general.

As a point of departure for the SIMS, the Directorate of Statistics embarked on the re-organisation of the geographic space of the Province in order to establish a comprehensive system of regions to provide a long-term base for producing and managing statistical information. As an initial step, the functions of the system of regions were identified and analysed; they are described below.

\section{Functions of Delimitation}

Partitioning the space of the Province into regions involves the concept of delimitation. Briefly delimitation involves the division of an area into units (in 
our case: regions) for a particular purpose (in our case: administration and delivery of services) with specific functions in mind. The actual drawing of boundaries between regions is called demarcation. The two concepts are not equivalent.

Delimitation of the Province was envisioned to serve eight functions. The first was to streamline distorted regional structures arising from the policy of apartheid on which quite a lot has been said above. Suffice it to reiterate that this function provides an imperative for re-organising the geographic space of the Province. In this respect not only should apartheid boundaries by streamlined, apartheid regions should be rationalised. Examples abound - such as the irregular boundaries at the interface between the former RSA whose regional structure was organised on the basis of functionality relative to urban centres, and the former Bophuthatswana homeland whose regional structures were organised on the basis of homogeneity. This explains the incidence of strange magisterial districts like Odi I and Odi II as well as the artificial boundary between the so-called different towns of TIhabane and Rustenburg. The principle proposes that a situation which entrenches or fossilises apartheid boundaries, for example, of former White towns and townships should be avoided. This applies to the hierarchy of urbanisation in which the centralplace-function criterion should be tempered by considerations of population size.

The second was to prepare for population censuses, with the 1996 Census immediately in mind. Delimitation for censuses is absolutely necessary in order for information on the population to be accurate and to be comparable over time. Given the underdeveloped nature of population registration in the North West Province, planning decisions have to be based on information from censuses. It is, therefore, imperative that such information should be accurate. Luckily it is becoming a tradition in South Africa to hold population censuses at relatively short intervals of every five or six years, unlike the standard ten-year intervals which are still characteristic of other developing countries. 
It is not a secret that in the recent past there has not been a comprehensive and accurate census of the majority population of South Africa. In the 1991 census in the former RSA the majority of the population was not enumerated, purportedly because of violence. Elsewhere in the former homelands the census was either a farce or had a relatively large undercount. A major reason for the undercount can be directiy traced to a lack of systematic delimitation (Kahimbaara, 1994a).

The third function is to prepare for elections, with the October 1995 Local Government Election immediately in mind. On the premise that the RDP is a policy framework for development in the Province, its implementation is bound to be undertaken mostly by local government structures. The spatial expression of these structures should determine the spatial organisation of a statistical information reporting framework, at least if the information is going to be useful in planning and decision-making in general. It is thus important that demarcation as provided for in the interim constitution should be part and parcel of the SIMS.

Fourth is the definition of statistical areas for sampling and censusing purposes. During intercensal periods statistical information for development planning and routine administration has to be collected largely from sample surveys and minor intra-territorial censuses. Definition of standard areas, called statistical areas, to constitute a provincial sampling frame is advantageous over the currently prevailing ad hoc approach of drawing samples. It also has advantages over the system of incomplete delimitation characterised by leakages, which was prevalent during the last census.

Fifth is the comparison of information on different services (such as statistical information on education, health and agriculture for the same area). On the assumption that the development effort is to be based on integrated planning, 
statistical information from different structures of government and different sectors of the economy in a given area should be linked.

Sixth is the generation of time-series data for purposes of constructing trends and monitoring change especially in the area of socio-economic development. Delimitation is necessary for the generation of consistent time-series data on any given area.

Seventh is the relating of information to its geographical source for planning purposes. Efficient use of statistical information in both routine administration and planning requires directly relating the information to its geographical source. This involves storage of such information on an electronic medium with geographic referencing facilities such as a Geographic Information System (GIS).

Eighth is reducing government expenditure by avoiding duplication of activities in the collection of data by different government structures. This is more of a benefit arising from the process of delimitation than a function of the process. Nevertheless a single statistical system would go a long way to effect savings of the taxpayer's money.

Together with these functions, the delimitation process was to be guided by a specific set of principles that would remain invariant over the entire geographic space of the Province.

\section{Principles of Delimitation}

The process of delimitation should be guided by the overall principle of good governance by which is meant the effective and efficient delivery of services by government to the populace. The services should increase the quality of life of the populace, in which case one should look at delimitation as providing a geographical framework for development and spatial planning. This principle subsumes four other sub-principles. First is decentralisation of government - 
government must go to the people for efficient delivery of services. Second is devolution of power and authority - there should be a democratisation of government processes. Third is that reconstruction and development should be community-based - delimitation should observe the tenets of the RDP, And fourth is non-partisanship in the process - the delimitation process should not be unjust (Kahimbaara, 1995b).

The delimitation process was further subjected to a set of constraints in order for it not to be disruptive ard costly.

\section{Parameters of the Delimitation Process}

Besides being guided by the above principles, the delimitation process should be developed within five parameters. Firstly, it should take into account progress aiready made in this direction. The process should incorporate positive developments and remove negative ones - for example, the existing spatial framework of urban settlements should form the basis for defining the system of regions, existing property boundaries should be respected, existing boundaries of traditional authorities should be respected, and as much of the existing boundaries should be used in order to maintain continuity in data collection by preserving the current data collection areal units. However, such negative features as irrational boundaries and unjustified magisterial districts should be eliminated.

Secondly, delimitation should facilitate the development of a system of regions. The delimitation process should not create a set of static regions, but a system of regions based on the same building block, in this case the enumeration subdistrict (ESD), which is floxible enough to allow for different regional configurations for the different functions of government while it still remains possible for statistical information botween them to be linked. The system should not only link up most public service activities but should also be 
sufficiently dynamic to create regions as required from time to time as long as the building blocks of the regions are not violated.

Third, delimitation should be based on a sound scientific basis. In order both to remain non-partisan and to provide an objective regional system, the scientific method was adopted for implementing the process. This constraint proposes that the process of delimitation and demarcation should demonstrate a sound scientific basis. It is essential for the sake of fairness to employ a delimitation procedure which is non-partisan. This is perhaps the most practical system available that leaves no room for the possibility of gerrymandering. In this respect it is important to suggest that the basic work of delimitation and demarcation should be done by a technical team rather than by politicians.

Fourthly, the delimitation process should be part of a process of consultation and negotiation, that is, the outcome of the scientific study should be democratised by subjecting it to scrutiny and criticism by the people to be aftected by the new system of regions recommended. Consensus on the proposed boundaries implies acceptance and ownership of the proposals by the people on the ground.

Fifthly, it should lead to a provincial-level one-stop statistical information service. In order to avoid duplication and to achieve cost effectiveness in government activities regarding statistical information, there should be a SIMS at the provincial level, which is where one finds the most comprehensive planning region below the nation level, to inform the various government structures. This would be in keeping with the objective of holism in the SIMS.

\section{Delimitation and Demarcation of the North West Province}

As already indicated, the delimitation and demarcation of the Province was initially seen as, and largely remained, a line function of the Directorate of Statistics in the Department of Economic Affairs. Later the Executive Council of 
the Province (Provincial Cabinet) took over responsibility for the project, assigning it to the Cabinet Committee on Social and Administrative Affairs for immediate supervision. The management of the Directorate of Statistics and PUCHE were constituted into a Technical Team to support the Demarcation Board in the Department of Local Government and Housing.

\section{Spatial Framework for the SIMS}

A spatial framework for the SIMS provides for the organisation of a system of regions from the provincial level to urban rural levels.

The spatial re-organisation of the North West Province was preceded by a regional study using the Central Place Model. The objective was to define areas of influence of the major urban centres in terms of the tenets of spatial interaction. In other words, the objective was to partition the Province into functional regions. This would be moving away form the intractable situation where, on re-incorporation of the former Bophuthatswana homeland to form a unified province, the regionalisation of the Province was characterised by a combination of functional and homogeneous regions which, as indicated earlier, are incompatible. Our view is that in the new situation the magisterial district boundaries, for example, do not make planning or indeed economic sense. They do not make regional scientific sense either (Geyer, et al, 1995). Before the advent of the homeland system, the South African regional system was functional, based on spatial interaction between urban nodes and their surrounding populations. However, with the advent of the homeland system, a system of homogeneous regions, based on the criterion of ethnicity, was superimposed on the system of functional regions. However, with the demise of apartheid as an official policy, the interface between the two systems appears grossly distorted. Among other examples, how does one explain the two Odi's in the North West Province, the three Lebowa's in the Northern Province, the two Mdantsane's and the two Queenstown's in the Eastern Cape, and so on? Not only is the distortion on the map, it is also economic and 
administrative. We believe it was the system rejected during the 1994 General Election and is likely to be rejected in the forthcoming Local Government Elections. The solution to these problems is proper delimitation and demarcation.

\section{Magisterial Districts}

The cut-off point of urban centres included in the study was the smallest magisterial district centre as the starting point of the study; the fulcrum of the delimitation process was the rationalisation of the magisterial districts on which past spatial distortion was centred. Urban centres in the study were ranked both on the basis of the services (central functions) they offered and their population sizes. With the use of Thiessen polygons the areas of influence of each urban area were delimited on a theoretical basis by computer. The computer results were then translated into practical recommendations by adapting tho boundary lines to farm and other property boundaries as well as to Iraditional authority boundaries, with the proviso that the existing magisterial district boumdarios aro used as much as possible in order to maintain continuity with past data colloction areas.

\section{District Councils}

Using a linear scale as well as a log-linear scale, rank-size distributions of the urban settlements were established. They both converged on the same five centres that were treated as regional centres or as district council centres. These are equivalent to the Regional Services Council centres.

The same methodology that was used to delimit magisterial district boundaries was applied to the definition of District Councils (which in effect are aggregations of a few magisterial districts). 


\section{Other Spatial Structures}

These include Transitional Local Councils (TLCs), Transitional Rural Local Councils (TRLCs), Enumeration Areas (EAs), Enumeration Sub-Districts (ESDs), and Election Wards. TLCs and TLRCs have mostly been completed, having had a significant input from the Demarcation Board. This, of course, is an indication that the process is not yet completed. ESDs which form the basic spatial building blocks of the regional system, EAs, wards, and so on, are currently being demarcated.

\section{Results of the Study}

As already pointed out, the study is not yet complete although there is no reason why it should not meet its targets and deadlines as originally planned. However, some of the results are out. The model rationalised the magisterial districts from a total of 27 to a total of 17 . These were subjected to a process of consultation and negotiation, resulting in the creation of an additional two, totalling 19.

\section{Likely Benefits of the SIMS}

It is important to note that the SIMS is greater than the process of spatial integration of the Province's geographic space. It involves the development of a GIS database and the geographical (re)organisation of the statistics system in the Province. However, the benefits are already apparent even before the system is completely in place. Several of these benefits may be mentioned. First, the administrative and planning space of the Province has been rationalised, with savings in human resources and administrative cost - the number of magisterial districts has been reduced by over 33 percent. Second, the spatial interaction between the population and urban centres has been maximised or near-maximised, thereby minimising aggregate travel costs. Third, boundaries that were responsible for marginalising former homeland areas have been removed in order to enhance the possibility of evening out the development surface. Fourth, the possibility of spatial conflict has been 
reduced as stakeholders own the process of delimitation. Fifth, undeserving district centres, the ones with more services than they deserve relative to their population size, have been superseded by more deserving centres. In this sense the delimitation process has already facilitated resource re-distribution. Sixth, administrative functions have been facilitated - District Council centres have been identified to facilitate local government administration as well as planning centres. This partly applies to magisterial district centres.

\section{CONCLUSION}

The main point made in this presentation is that if South African society is to rid itself of the legacy of the past policy of apartheid, then spatial re-organisation of the provinces has to be given as much priority as the removal of apartheid legislation and the restructuring (and rationalisation) of public institutions. Development infrastructure is deployed on the ground. Implementation of the RDP both as a framework for development and as a programme of projects assumes such spatial re-organisation. The contribution of statisticians could be for them to make sure that every piece of South African territory is associated with information intended for the RDP. They should not continue, especially those in control of GISs, to reconfirm spatial apartheid by producing maps based on the old order spatial configuration. It is as much the statistician's responsibility to be pro-active as it is the politician's. The latter can be advised.

\section{REFERENCES}

[1] Geyer, H.S., Drewes, J.E., and Oosthuizen, L., A Statistical Information Management System for the North West Province, Phase I: Delimitation of Magisterial Districts, Institute of Urban and Regional Planning, Potchefstroom University, Potchefstroom. (1995).

[2] Kahimbaara, J.A., Some aspects of the accuracy of censuses in a Third World Setting: the 1991 Censuses of Transkei and Bophuthatswana. A paper presented to a Conference of the Demographic Association of 
68

Southern Africa, on Demographic Challenges for Southern Africa. The Development Bank of Southern Africa, Midrand, 14-15 July, (1994a).

[3] Kahimbaara, J.A., Comments on delimitation of the North West Province (Unpublished) Department of Economic Affairs, North West Province, (1994b). 